\title{
Abdominal wall integrity and cosmetic outcome after minicholecystectomy incision with half rectus muscle preservation
}

\author{
Mohamed Ahmed Megahed, MD
}

\author{
Department of Plastic Surgery, Menoufiya University, Egypt.
}

\section{Correspondence:}

Dr. Mohamed Ahmed Megahed, Assistant Professor of Plastic Surgery,

Menoufiya University Hospitals, Tel. +20105268496; E.mail: megahedmaa@yahoo.com

\begin{abstract}
Background: Today the removal of the gallbladder is the safest, the most effective and widely recommended treatment for gallstone disease. Three essential methods are used for removal of the gallbladder: standard open cholecystectomy, laparoscopic cholecystectomy and minicholecystectomy. Traditionally, the surgical community has resisted accepting minicholecystectomy.

Aim of the work: Evaluation of the efficiency of minicholecystectomy incision with half rectus muscle preservation in improving abdominal wall integrity and cosmetic outcome after cholecystectomy incision.

Patients \& methods: Thirty seven patients had undergone cholecystectomy with a mini incision in Menoufiya University Hospital from September 2006 to May 2008. Their age ranged from 24 to 58 years old. The follow up period was one year.

Results: As regard early wound complications there were no subcutaneous haematomas, only one case of wound sepsis and two cases of seroma that were managed conservative. Late wound complications included two cases of hypertrophic scar. No angular wound dehiscence or incisional hernia. The scar was small with good cosmetic outcome and almost all patients were satisfied with the scars.

Conclusion: Minicholecystectomy incision with preservation of half the rectus muscle improves the abdominal wall integrity \& cosmetic outcome.

Key words: Minicholecystectomy, Preservation, Rectus.
\end{abstract}

\section{Introduction:}

Today the removal of the gallbladder is the safest, the most effective and widely recommended treatment for gallstone disease. Three essential methods are used for the removal of the gallbladder: Standard open cholecystectomy, laparoscopic cholecystectomy and minicholecystectomy. Traditionally, the surgical community has resisted accepting minicholecystectomy. ${ }^{1}$

The use of minimally invasive techniques as in laparoscopic cholecystectomy have the advantage of reduced hospital stay because of less pain, smoother postoperative convalescence thus allowing early return to work, and the better cosmetic results. ${ }^{2}$ However, laparoscopic dissection may be hazardous and the operating time is significantly prolonged in patients with thickwalled, inflamed or adherent gall bladders. ${ }^{3}$

In abdominal surgery, wisely chosen incisions and correct methods of making and closing such wounds are factors of great importance. ${ }^{4}$ Any mistake, such as a badly placed incision, or methods of suturing, or illjudged selection of suture material, may result in serious complications such as haematoma formation, an ugly scar, an incisional hernia, or, worst of all, complete disruption of the wound. ${ }^{5}$

On the basis of this prospective randomized study, the hypothesis that a smaller incision length on the abdominal wall could lower the level of perceived pain, and therefore decrease 
the postoperative analgesic intake after minicholecystectomy, could not be confirmed. ${ }^{6}$

\section{Aim of the Work:}

Evaluation of the efficiency of minicholecystecomy incision with half rectus muscle preservation in improving abdominal wall integrity and cosmetic outcome after cholecystectomy incision.

\section{Patients and methods:}

Thirty seven patients had undergone cholecystectomy with a mini incision in Menoufiya University Hospital from September 2006 to May 2008. Their age ranged from 24 to 58 years old. The follow up period was one year.

\section{Technique, Figures(1-3):}

- Preoperative preparation like non-residence diet for 48 hours and drugs like intestinal antiseptics before operation.

- Anaesthesia: general endotracheal anaethesia.

- Position: supine.

- Sterilization and towling.

- Incision: transverse right subcostal skin incision length ranges $(4.5-5.7 \mathrm{~cm})$. But this small incision is not suitable for very long obese patients. Cutting subcutaneous tissue and anterior abdominal wall musculature with preservation of the medial half of rectus abdominis muscle to preserve the anterior abdominal wall integrity and the superior epigastric vessels to maintain the blood supply of the anterior abdominal wall and prevent the angular wound dehiscence aiming to reduce the incisional hernia postoperative and improve the cosmetic outcome after cholecystectomy. A drain is left. Closure of the wound is done in layers: Peritoneum closure with Vicryl 1/0, muscle layers with prolene 1, then subcutaneous and skin with Vicryl 4/0 subcuticular sutures.

\section{Postoperative:}

Postoperative treatment included analgesic paracetamol infusion, antibiotics, (3rd generation cephalosporin) and intravenous fluids. Oral feeding was started after regain of intestinal movements. Drains were removed after 48 hours, follow up for wound complication and cosmetic outcome continued for one year.

\section{Results:}

Operative complications: 2 cases of bleeding, one case of bile duct injury, no cases of bowel injury. Postoperative complications: 3 cases of biliary leak and 5 cases of pulmonary \& cardiac complications Table(1).

As regard early wound complications no subcutaneous haematomas, only one case of wound sepsis and 2 cases of seroma that were managed conservative. Late wound complications included 2 cases of hypertrophic scar. No angular wound dehiscence or incisional hernia, small scars with good cosmetic outcome and most patients were satisfied with the scars Tables $(2,3)$.

Table (1): Operative and postoperatrive complications.

\begin{tabular}{|l|c|}
\hline Complication & Incidence \\
\hline Bleeding & 5.4 \\
Bile duct injury & $2.7 \%$ \\
Bowel injury & $0 \%$ \\
Biliary leake & $8.1 \%$ \\
Pulmonary complications & $7.1 \%$ \\
Cardiac complications & $2.7 \%$ \\
Thromboembolism & $0 \%$ \\
\hline
\end{tabular}


Table (2): Incidence of early and late wound complications.

\begin{tabular}{|l|c|}
\hline Wound complications & Incidence \\
\hline 1. Wound sepsis & $5.4 \%$ \\
2. Seroma & $2.7 \%$ \\
3. Subcutaneous haematoma & - \\
4. Hypertrophic scar & $5.4 \%$ \\
5. Angular wound dehiscence & - \\
6. Incisional hernia & - \\
\hline
\end{tabular}

Table (3): Patients and clinical data.

\begin{tabular}{|l|c|}
\hline Patients & Clinical Data \\
\hline 1. Mean age & $42 \pm$ years old \\
2. Mean length of skin incision & $5.2 \mathrm{~cm}$ \\
3. Cosmotic outcome of scars & Excellent \\
4. Patient satisfaction with scars & $86.5 \%$ \\
5. Mean hospital stay & 2 days \\
\hline
\end{tabular}

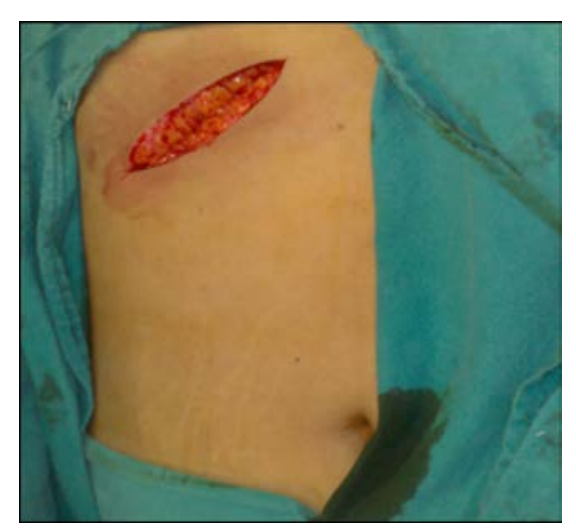

Figure (1): Minicholecystectomy incision.

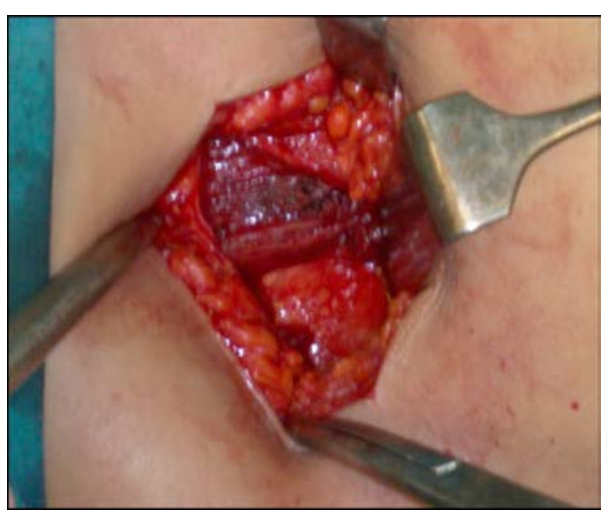

Figure (2): Preservation of the medial half rectus muscle and removal of the gall bladder.

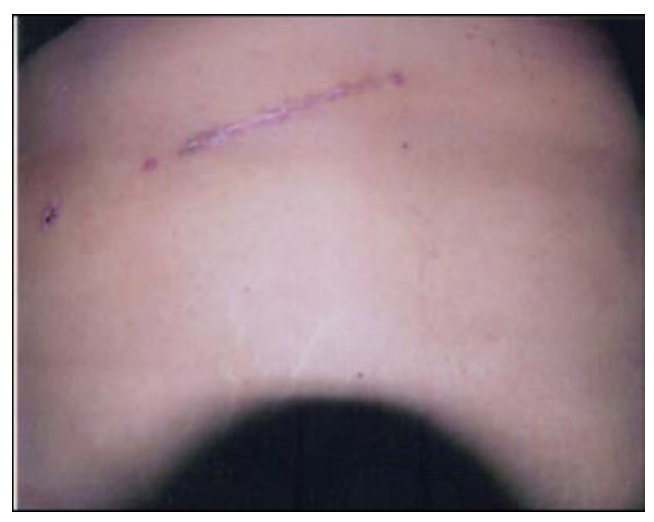

Figure (3): Minicholecystectomy incision postoperative. 


\section{Discussion:}

In abdominal surgery, wisely chosen incisions and correct methods of making and closing such wounds are factors of great importance. ${ }^{4}$

Any mistake, such as a badly placed incision or methods of suturing, or ill-judged selection of suture material, may result in serious complications such as haematoma formation, an ugly scar, an incisional hernia, or, worst of all, complete disruption of the wound. ${ }^{5}$

At present, the laparoscopic approach is the method of choice for cholecystecomy. ${ }^{4,7}$ In this study shortening the skin incision and preservation of the medial half of rectus abdominis muscle significantly reduces angular wound dehiscence and incisional hernia postoperative and these results coincide with the results of Ros et al. ${ }^{8}$ who concluded that surgical trauma is greater after conventional open cholecystecomy than after minilaparotomy cholecystectomy.

Also, the cosmetic outcome is improved and near all patients were satisfied with their scars and these results are similar to that of Assalia et al. ${ }^{5}$ who concluded that minicolechystectomy offers better cosmetic results than open conventional cholecystectomy. The same results were also obtained by El-Ghareeb and Said ${ }^{9}$ in improving the cosmetic outcome after mini-cholecystectomy. Moreover, preservation of superior epigastric vessels allows the patient to do another exploratory midline incision at any time without risk of triangular necrosis. Furthermore, rectus flap is preserved for breast and chest wall reconstruction.

The incidence of postoperative subcutaneous haematoma is reduced due to decreased surgical trauma as in the results of Ros et al. ${ }^{8}$ and due to preservation of the superior epigastric vessels in the preserved medial half of rectus but this is controversed by the results of El-Ghareeb and Said. ${ }^{9}$ who stated that subcutaneous haematoma is more in mini-cholecystectomy incision due to vigorous retraction but in this study preservation of the superior epigastric vessels in the medial half of rectus abdominis was not affected by retraction. Postoperative analgesia, cost and mean hospital stay not significantly changed like with Schmitz et al. ${ }^{6}$

Incidence of operative and postoperative complications showed no sigificant change in comparison with the results of Ros et al. ${ }^{8}$ for open conventional cholecystectomy.

\section{Conclusion:}

Minicholecystectomy incision with preservation of half the rectus muscle improves the abdominal wall integrity \& cosmetic outcome.

\section{References:}

1- Rozos I, Ferenczy J, Schmitz R: Micro and mini-cholecystectomies in the 21 st century. Orv Hetil 2003; 144(26): 1291-1297.

2- Keane FBV, Tanner WA, Darzi A: Alternatives to cholecystectomy for gallbladder stones. In: Recent advances in surgery. Taylor I and Jhonson CD (Editors); Churchill Livingstone (Publisher); 1991; p. 1-16.

3- Majeed AW, Reed, MWR, Johnson AG: New approaches to gallstones: A balanced view. In: Current Surgical Practice. Hobsley M, Johnson AG, Treasure T (Editors); Hodder \& Stoughton (Publishers); 1993; p. 59-79.

4- Neugebauer E, Troid H, Spangenberger W, Dietrich A, Lefering R: Conventional versus laparoscopic cholecystectomy and the randomized controlled trial. Cholecystectomy study group. Br J Surg 1991; 78: 150-154.

5- Assalia A, Schein M, Kopelman D, Hashmonai M: Minicholecystectomy vs conventional cholecystectomy: A prospective randomized trial, implications in the laparoscopic era. World J Surg 1993; 17(6): 755-759.

6- Schmitz R, Rohde V, Treekmann J,Shah S: Randomized clinical trial of conventional cholecystectomy versus minicholecystectomy. Br J Surg 1997; 84(12): 1683-1686.

7- Unger SW, Rosenbaum G, Unger HM, Edelman DS: A comparison of laparoscopic and open treatment of acute cholecystitis. Surg Endosc 1993; 7: 408-411.

8- Ros A, Carlsson P, Rahmqvist M, Bäckman $\mathrm{K}$, Nilsson E: Non-randomised patients in a cholecystectomy trial: Characteristics, procedures, and outcomes. BMC Surgery 2006; 6:17.

9- E1-Ghareeb MH, Said TA: Minicholecystecomy versus conventional cholcystectomy. The postoperative period. Egypt J Surg 1999; 18(1): 51-58. 